\title{
Observation and contagion effects in cooperation: An Experimental Investigation
}

\author{
Edward Cartwright ${ }^{1}$ \\ Thomas Singh ${ }^{2}$ \\ $29^{\text {th }}$ March 2018
}

Keywords: Social interactions effects; social norms; stag hunt game; prisoners dilemma; minimum effort game; contagion.

JEL codes: D10, C72, C92, H41

\begin{abstract}
We experimentally disentangle two potential sources for endogenous social interactions effects. By comparing groups where the aggregate behavior is publicly observable with those where it is not we can measure the size of any endogenous observation effect. By comparing connected with disconnected groups we can measure the size of any endogenous contagion effect. Results are provided for both a coordination game and social dilemma. We find strong evidence of an endogenous observation effect in the coordination game but not social dilemma. We find no evidence of an endogenous contagion effect in either game. While our results point towards a conformity effect we argue that information on group behavior primarily acts as a coordinating device which may be reflected in changes in beliefs.
\end{abstract}

Acknowledgments: This work was supported by a British Commonwealth Academic Fellowship for Thomas Singh. We would also like to thank seminar participants at the University of Nottingham and University of Kent for comments. We also thank two anonymous referees for their comments an earlier version of the paper.

The final version of this paper was published in the Journal of Experimental and Behavioral Economics, Eslevier, https://doi.org/10.1016/j.socec.2018.04.006.

\footnotetext{
${ }^{1}$ Department of Strategic Management and Marketing, De Montfort University, Leicester, LE1 9BH, UK.

${ }^{2}$ Department of Economics, University of Guyana,Georgetown, Guyana.
} 


\section{Introduction}

There is now considerable interest in the interactions based approach to socioeconomic behaviour (e.g. Blume and Durlauf 2004; Durlauf and Ioannides 2010). The basic objective is to explore group influence on things like effort in the workplace, high school dropout rates, or tax evasion. Empirically disentangling group influence is complicated by many problems, most notably, issues of identification (Manski 1993, 2000). ${ }^{3}$ Laboratory experiments enhance the identification of endogenous social interactions effects by allowing us to circumvent unobservable contextual and correlated effects (Castillo and Carter 2007, Fortin, Lacroix and Villeval 2007, Falk, Fischbacher and Gächter 2013). They also allow us to address issues that simply cannot be addressed in the field. In particular, Blume et al. (2011) highlight the need to distinguish and disentangle the many possible sources of endogenous effect (see also Young 2009) and the lab provides an environment to explore such issues.

One possible source of endogenous effect is, what we shall refer to as, an observations effect. The idea here is that an individual is influenced by what he observes others doing. For example, Fred might drop out of school early if he observes friends doing so, or Maria might diligently fill in her tax return because she observes her colleagues doing so. Broadly speaking this could reflect social preferences or social learning. Fred, for instance, may drop out of school because he wants to conform with school friends - social preferences - or because the actions of others change his beliefs about the merits of education - social learning (Manski 2000). In a setting with little or no strategic interdependence, like school attendance and tax evasion, it seems natural to think of the observations effect as the main channel through which endogenous effects may arise (e.g. Fortin et al. 2007). ${ }^{4}$ There is, however, also considerable interest on endogenous social interaction effects in settings with higher levels of strategic interdependence. ${ }^{5}$ In these settings, as we shall shortly discuss, alternative effects may come to the fore.

\footnotetext{
${ }^{3}$ While great strides have been made in recent years in overcoming these problems empirical evidence on interactions remains controversial (Blume and Durlauf 2006; Graham 2008; Blume et al. 2011).

${ }^{4} \mathrm{We}$ informally equate strategic interdependence with a person's payoff depending on others actions. The returns to education and the likelihood of tax audit may depend on the actions of others but the effect of any one person is likely to be very small.

${ }^{5}$ Consider, for instance, teenage pregnancy. Pregnancy is a clearly a process that involves two independent decision makers with a high degree of strategic interdependence. These two actors make their decisions in a broader social environment where they can observe the decisions of friends and family.
} 
The particular example we shall focus on here is that of cooperation with others. Consider, for instance, a university where faculty are regularly interacting in small groups on collaborative projects through research centres, committees and so on. For the sake of argument suppose, as seems reasonable, that the payoff of an academic depends solely on the projects that he is directly involved in, rather than the overall performance of the university. How hard will academics work? There are clear strategic reasons why the effort of academics within any particular project may become homogenous as the group converges to an equilibrium (e.g. Devetag and Ortmann 2007). For instance, a person may slack on a project if others are doing so. To speak of an endogenous social interactions effect we are interested in spillovers in behaviour across projects.

To see how this might happen consider Figure 1 in which we compare two universities. In University 1 there are four academics, A, B, C and D, and two projects. Academics A and B work together and $\mathrm{C}$ and D work together. In a benchmark case where A and B cannot observe the effort of $\mathrm{C}$ and $\mathrm{D}$ then there is simply no mechanism whereby the effort of $\mathrm{A}$ and $\mathrm{B}$ can be influenced by the effort of $\mathrm{C}$ and $\mathrm{D}$, and vice versa. So, the outcome in each group must be independent. Now, suppose that academics A and B can observe the effort of C and D. For instance, they see publication or funding outcomes of colleagues. This can result in an observations effect whereby the effort of A and B is influenced by what they observe of C and D. Academics A and B may, for example, work harder if they observe $\mathrm{C}$ and $\mathrm{D}$ being successful. This could reflect social preferences, such as envy at the success of others, or social learning, such as a change in beliefs about the chances of success. As such, it would fit the standard story of an endogenous social interactions effect.

Figure 1: A schematic of two universities.

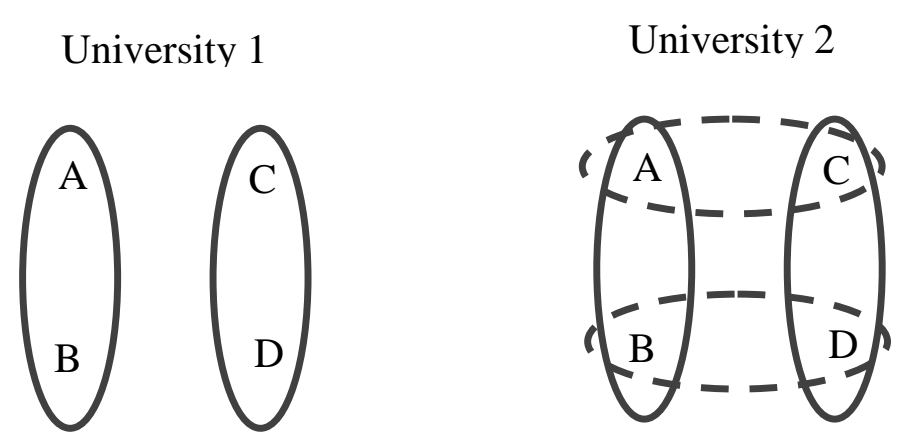


University 2 still has four academics, A, B, C and D, but now has a more complex interaction structure. Specifically, academic A sometimes works with B and sometimes with C while academic D works sometimes with $\mathrm{C}$ and sometimes with $\mathrm{B}$. Note that $\mathrm{A}$ and $\mathrm{D}$ do not directly interact (neither do B and C) but they do indirectly interact through B and C (or A and D). This indirect interaction can lead to a contagion effect (or behavioural cascade) whereby behaviour spreads across projects (Fowler and Christakis 2010). For example, academic A may exert high effort on a project with $B$ because he recently benefited from exerting high effort on a project with C. Note that a contagion effect is independent of an observations effect because it does not require that an academic observes the effort of other projects. He simply learns from his own experience of working across different projects. Even so, it may still reflect social preferences or social learning. Contagion effects have been widely studied in the game theoretic literature on networks (e.g. Ellison 2000, Morris 2000, Boyer and Jonard 2014) but received little attention in the literature on social interactions.

Both an observations effect and a contagion effect can lead to endogenous norms. For instance, in the university example we may see convergence on similar effort levels across different projects. The mechanism through which this happens is, however, very different depending on whether the observations or contagion effect is prominent, and this may prove important in application (Young 2009). Suppose, for example, a group has converged on an inefficient norm of low effort and an employer, department chair or policy maker wants to 'switch' the group to a more efficient norm. The ease with which this can be done, and the best way to achieve it, may critically depend on whether an observations or contagion effect drives behavior. An observations effect means that information is of crucial importance. A contagion effect, by contrast, means that network structure is crucial (e.g. Keser, Erhart and Berninghaus 1998). Note that it may also be important to also discern whether social preferences or social learning are key driving factors in whatever effect is observed (Bicchieri 2018).

In order to disentangle the observation and contagion effect our experiment employs a $2 \times 2$ between-subject design. In groups of four, subjects interact pairwise by playing either a coordination game or social dilemma. In the benchmark treatment subjects did not observe and did not interact with others in their group. As such, social interaction effects cannot be the cause of any correlation in behaviour across the group. Specifically, thinking in terms of University 1, the A-B pair and C-D pair never interact in any way and so if they, say, both converge on mutual high 
effort this cannot be because of spillover effects. In the three remaining treatments subjects observed others and/or indirectly interacted with all others in the group. Comparison of outcomes in these treatments with our benchmark treatment allows us to directly test for an observations and/or contagion effect. Our main finding is of a strong endogenous observations effect in the coordination game. This has the effect of significantly increasing cooperation levels. We do not find evidence of an observation effect in the social dilemma game. Nor do we find any evidence of a contagion effect in either the coordination or social dilemma game.

We shall relate our work to that of the existing literature as we proceed. But it may help to clarify at this stage that our paper fits within two strands of literature. In terms of motivation our paper is most closely related to the emerging literature on endogenous social interactions effects in the lab (e.g. Fortin et al. 2007, Cooper and Rege 2011, Falk et al. 2013). In terms of design our experiment is most closely related to the literature on network games (e,g, Berninghaus, Ehrhart and Keser 2002, Cassar 2007, Frey, Corten and Buskens 2012, Antonioni et al. 2013). What distinguishes our approach is the way it builds upon both these literatures. In particular, work on endogenous social interactions effects has largely ignored the role of contagion, while work on network games has largely ignored the role of social influence. Our approach is designed so that both effects can be compared.

In order to justify this latter claim we highlight that allowing for both an observation and contagion effect is the main novelty in our approach. To the best of our knowledge, prior studies focus on only one of these possibilities. For instance, Fortin et al. (2007), Cooper and Rege (2011) and Gächter et al. (2013) consider settings where subjects observe group outcomes but do not interact, directly or indirectly, with everyone in the group. By contrast, Berninghaus, Ehrhart and Keser (2002), Fowler and Christakis (2010) and Falk et al. (2013) consider settings where subjects indirectly interact with everyone in the group but do not observe group outcomes. ${ }^{6}$ Allowing for both observation and contagion effects is a natural next step. Our design allows us to distinguish the effect of each.

We proceed as follows. In sections 2 and 3 we introduce the experimental design, in section 4 we provide our results and in section 5 we conclude.

\footnotetext{
${ }^{6}$ Group here should be read as the extended group with whom players indirectly interact. What Falk et al. (2013) call a matching group. We discuss this more in the conclusion.
} 


\section{Experiment design}

At the beginning of an experimental session subjects were randomly assigned to a group of four and given a label A, B, C or D. Over 20 periods the subjects were then matched in pairs (more on this shortly) to play the coordination game given in Table 1. The group and labels remained fixed throughout the 20 periods. The coordination game played is a version of the minimum effort game or stag-hunt where mutual cooperation and mutual non-cooperation are Nash equilibria (Devetag and Ortmann 2007). ${ }^{7}$ We chose this game because the literature on contagion effects has mainly focussed on such games (Weidenholzer 2010). Moreover, the existence of multiple equilibria is useful in looking for social interaction effects because it suggests there will be heterogeneity in behaviour. $^{8}$

Table 1. The coordination game and social dilemma game used.

Coordination game

(Part 1: periods 1-20)
Social dilemma

(Part 2: periods 21-40)

\begin{tabular}{|c|c|c|c|c|c|}
\hline & & \multirow{2}{*}{\multicolumn{2}{|c|}{ Player 2}} & \multirow{2}{*}{\multicolumn{2}{|c|}{ Player 2}} \\
\hline & & & & & \\
\hline & & Cooperate & $\begin{array}{c}\text { Not } \\
\text { cooperate }\end{array}$ & Cooperate & $\begin{array}{c}\text { Not } \\
\text { cooperate }\end{array}$ \\
\hline & Cooperate & 130,130 & 10,70 & 100,100 & 25,125 \\
\hline Player 1 & $\begin{array}{c}\text { Not } \\
\text { cooperate }\end{array}$ & 70,10 & 70,70 & 125,25 & 50,50 \\
\hline
\end{tabular}

In addition to a coordination game we also wanted to look at outcomes in a social dilemma. So, after 20 periods, subjects were randomly reassigned a new group and label and over a subsequent 20 periods were matched to play the social dilemma game given in Table $1 .{ }^{9}$ This game

\footnotetext{
${ }^{7}$ We can equate cooperation with an effort level of 2 and non-cooperation with an effort level of 1 . The payoff of member $A$ when matched with member $B$ is $\pi_{A}=10+120 \min \left\{e_{A}, e_{B}\right\}-60 e_{A}$ where $e_{A}$ and $e_{B}$ are the effort of members $A$ and $B$.

${ }^{8}$ If everyone in the group initially behaves in the same way then there is no realistic hope of picking up a social interaction effect. Heterogeneity of behaviour is, therefore, essential.

${ }^{9}$ At the start of the session subjects were only given instructions corresponding to the first part of the experiment (they were told there would be a second part to the experiment). After period 20 had finished subjects were given the instructions corresponding to the second part of the experiment. In these instructions it was emphasized to subjects that they would be playing a different game with a different group of people. Clearly, one cannot rule out the
} 
is a version of a linear public good game or Prisoners Dilemma where mutual non-cooperation is the unique equilibrium. ${ }^{10}$ Given that this game has a unique equilibrium (in material payoffs) it is, at face value, less interesting for studying social interaction effects. In particular, homogeneity of behaviour can be expected for strategic reasons. It has, however, long been recognised that social preferences for, say, reciprocity can result in multiple equilibria (e.g. Dufwenberg and Kirchsteiger 2004). Hence, we may observe social interaction effects (Falk et al. 2013). Indeed, it is plausible that social interaction effects could increase the likelihood of mutual cooperation.

Note that the language used in the instructions was deliberately neutral, using $\mathrm{X}$ and $\mathrm{Y}$ rather than cooperate and non-cooperate. Also, the payoff values for both games were chosen with the hope of obtaining around 50 percent cooperation in the first and $21^{\text {st }}$ period (which was indeed the case). To obtain 50 percent cooperation is ideal, for our purposes, because it means there is maximal heterogeneity of behaviour and therefore considerable potential for social interaction effects.

We ran four treatments employing a $2 \times 2$ between subject design in which (1) the network of strategic interaction and (2) information on the group norm varied as we now explain.

The two networks of strategic interaction were: (a) If the group is not-connected then in every period member $A$ meets member $B$ and member $C$ meets member $D$. This corresponds to University 1 in Figure 1. (b) If the group is connected then in every odd numbered period member $A$ meets member $B$ and member $C$ meets member $D$, and in every even numbered period member $A$ meets member $C$ and member $B$ meets member $D$. This corresponds to University 2 in Figure 1 . Irrespective of whether the group is connected or not each group member strategically interacts with a strict subset of the group. Member $A$, for instance, never meets member $D$. The difference between the connected and non-connected group is whether there exists a path of strategic interaction between every two group members. In a connected group, for instance, member $A$ meets members $B$ and $C$ who each meet member $D$.

The two levels of information on group behavior were: (i) If group history is not observable then a group member is only given feedback on the outcome of their own strategic interaction. For

\footnotetext{
possibility of some order effect between parts 1 and 2 of the experiment. We shall return to this issue when analyzing the results.

${ }^{10}$ We can equate cooperation with contributing 1 to the public good and non-cooperation with contributing 0 . The payoff of member $A$ when matched with member $B$ is $\pi_{A}=75\left(c_{A}+c_{B}\right)+100\left(1-c_{A}\right)-50$ where $c_{A}$ and $c_{B}$ are the contributions of members $A$ and $B$.
} 
instance, if member A meets member $B$ then, at the end of the period, he is given feedback on the choice of $B$. (ii) If group history is observable then in each period members of the group were also shown a table detailing the number of group members who cooperated and did not-cooperate in each period to date. ${ }^{11}$ Crucially, if history is observable then a group member is exposed to more information about the group than when history is not observable (even if the group is connected). For instance, if member $A$ meets member $B$ then he directly observes the action of member $B$ and can also infer the outcome from member $C$ and $D$ s interaction.

In order for the treatments to be comparable the instructions given to subjects were kept the same throughout. Specifically, subjects were told that they were in a group of 4 and that they would be matched with other members of the group. In each period a subject was then told the identity $(A, B, C$ or $D)$ of the member they would interact with in that period. Clearly, subjects may realize the pattern as to whom they meet in each period. They cannot be sure, however, that this pattern is not going to change. ${ }^{12}$

The experiments took place at the University of Kent in the UK. We had 7 groups for each treatment with a total of 112 subjects participating, recruited from across the university. Interaction was anonymous by computer. The experiments were programmed in $z$-Tree (Fischbacher 2007). A session lasted around 40 minutes with the average subject earning $£ 11.10$.

\section{Hypotheses on endogenous social interaction effects}

Consider group member $A$ (in any of the treatments). Given that members $A$ and $B$ meet there are clear strategic reasons why the behaviour of $A$ may be influenced by that of $B$. For example, member $A$ may choose to not cooperate if $B$ has not cooperated in the past. This, of itself, could be interpreted as a social interaction effect (see, in particular, Falk et al. 2013). Our interest here, however, is on spillover effects that are not a consequence of direct strategic interests. For example, we are interested in whether the behaviour of member $A$ may be influenced by member $D$ even

\footnotetext{
${ }^{11}$ We gave information on both cooperation and non-cooperation in order to avoid a framing bias. The sum is always four.

12 The not-connected treatment involves partner matching. The connected treatment is a form of stranger matching. We know that cooperation is generally lower in stranger than partner matching (e.g. Duffy and Ochs 2009). Given, however, that subjects were given identical instructions and the group has only four members this effect should be mitigated. In particular, each interaction takes place at least 10 times. Moreover, subjects were always told the identity of the group member they were interacting with and so the 'stranger' element is essentially removed.
} 
though they never meet. In order to look at this issue we can compare behaviour in A-B and C-D pairs.

In the not-connected and no-history setting there is simply no channel whereby the A-B pair can be influenced by the decision in the C-D pair, and vice-versa. This may seem contra to the notion of group. It is not unreasonable, however, to imagine members of group who share some common identity, e.g. academics at a particular university, while never interacting with each other either directly or indirectly. Given that the A-B and C-D pairs are isolated from each other any correlation in their behaviour must be due to a contextual or correlated effect. ${ }^{13}$ The not-connected and no-history setting is, thus, the natural benchmark.

Note that in setting this treatment up as the benchmark we impose no a-priori assumptions on what will happen within pairs. Pairs may converge on mutual cooperation, mutual noncooperation or otherwise. And behaviour may be driven by strategic material considerations, social preferences or otherwise. The key thing for our purposes is that outcomes provide a unit of comparison in which we know that observing or indirectly interacting with others cannot be relevant. That said, in the ideal world we would see half the pairs exhibit mutual cooperation and half mutual non-cooperation. This would allow for maximal baseline heterogeneity at the pair level, allowing us to measure spillovers when observation and indirect interaction do take place.

Contrast the benchmark setting with the not-connected and history treatment. The chance to observe history creates a link between the A-B and C-D pairs. Member A, for example, can infer something about the behaviour of members $C$ and $D$. One could argue that there is no reason for member $A$ to be influenced by this information as she only ever strategically interacts with member $B$. This motivates the following null hypothesis:

Hypothesis 1: In the not-connected and history setting, the decisions of the A-B and C-D pairs are independent of each other.

Hypothesis 1 can be tested by comparing the not-connected and history treatment with the benchmark, not-connected and no-history treatment. Any differences between these treatments would suggest that behaviour is influenced by observing others.

\footnotetext{
13 The random assignment of subjects to groups should rule out correlated effects (with a sufficiently large number of observations). Contextual effects are possible; for instance, if different sessions are run at different times of the day this may change behaviour. Again, however, a random assignment of subjects to treatments should rule this out.
} 
We say that there is an observations effect if one group member, say $A$, is influenced by observing the behaviour of group members with whom he does not interact, $C$ and $D$. Note that an observations effect simply cannot happen, by construction, in the not-connected and no-history setting. It can happen in the not-connected and history treatment. Rejection of hypothesis 1 would, therefore, be consistent with an observations effect. And a positive correlation between pairs would be consistent with an endogenous social interactions effect as typically alluded to in the literature (Blume and Durlauf 2004). As already said, this could reflect social preferences or social learning. There is extensive evidence of peer influence in various contexts (e.g. Falk and Ichino 2006, Shang and Croson 2009, Gächter, Nonsenzo and Sefton 2013, Thöni and Gächter 2015) and this may lead to an observations effect. It is, however, worth noting that there are contexts where an observations effect has not been found (e.g. Fortin et al. 2007).

Consider next the connected and no-history setting. In this setting there is a channel of strategic interaction whereby the A-B pair can be influenced by the C-D pair, and vice-versa. For example, member $A$ 's choice of action when she meets member $B$ may be influenced by the experience she had when meeting member $C$. Members can, however, choose to condition action on the member with whom they are interacting (Falk et al. 2013, Berninghaus et al. 2014). Again, therefore, one can motivate a null hypothesis of no influence:

Hypothesis 2: In the connected and no-history setting, the decisions of the A-B and C-D pairs are independent.

Hypothesis 2 can be tested by comparing the connected and no-history treatment with the benchmark, not-connected and no-history treatment. Any differences between these treatments would suggest indirect influence through network effects in the group.

We say that there is a contagion effect if behaviour spreads across the group through strategic interaction (e.g. Morris 2000, Cassar 2007, Fowler and Christakis 2010). For instance, there is a contagion effect if member $A$ 's behaviour is influenced by the past behaviour of member $D$, because of the effect $D$ 's behaviour has had on $B$ and $C$. Note that, by construction, a contagion effect cannot happen in the two no-connected settings. Rejection of Hypothesis 2 would be consistent with an endogenous contagion effect. ${ }^{14}$ Evidence consistent with a contagion or

\footnotetext{
${ }^{14}$ Contagion is typically defined as the use of an action spreading from a 'small subset' of the group to a large proportion of the group. Given that we consider groups of four members this definition has to be interpreted loosely as meaning the action of one or two members spreading to others in the group.
} 
spillover effect has been observed in various settings (e.g. Duflo and Saez 2003, Fowler and Christakis 2010). Again, however, it is worth noting that there are examples where a contagion effect was not found (e.g. Falk et al. 2013).

Finally, consider the connected and history setting. Clearly this setting allows for both an observational and strategic channel of influence between A-B and C-D pairs. Our null hypothesis remains that these channels do not influence behaviour.

Hypothesis 3: In the connected and history setting, the decisions of the A-B and C-D pairs are independent.

There are various alternative hypotheses one could consider here. For instance, if we accept hypotheses 1 and 2 but reject hypothesis 3 this would suggest an endogenous social interactions effect caused by the interplay between social and strategic interaction. Let us reiterate at this point that the key novelty in our approach is an experimental design that allows for both an observation and contagion effect and allows us to distinguish between them.

\section{Experimental Results}

Figure 2 plots the proportion of subjects choosing cooperation distinguished by treatment. In periods 1 and 21 around 50 percent of subjects cooperate and there is no significant difference between treatments ( $\mathrm{p}=0.54$, LR test). ${ }^{15}$ This is exactly as we hoped as there is maximal heterogeneity within groups.

In the coordination game we observe noticeably higher cooperation in the two history treatments compared to the no history treatments. This difference is marginally significant by the third period ( $\mathrm{p}=0.09$, LR test), highly significant by the fifth period $(\mathrm{p}<0.01)$ and remains significant in every subsequent period ( $\mathrm{p} \leq 0.06$ ). By contrast, there is no apparent difference between the two connected treatments and the not-connected treatments ( $\mathrm{p}>0.1$, all periods). In the social dilemma game we observe a familiar downward decline in cooperation (Fischbacher and Gächter 2010) with no evidence of any significant difference between treatments ( $p>0.1$, LR test, all periods).

\footnotetext{
${ }^{15}$ For this test, given that it is the first period, we use the individual as the unit of observation. Unless, otherwise specified, all subsequent tests use the group as the unit of observation. All tests are two-sided.
} 
Figure 2: The proportion of subjects who cooperated by treatment in the (a) coordination game (periods 1 to 20) and (b) social dilemma (periods 21 to 40).

(a)

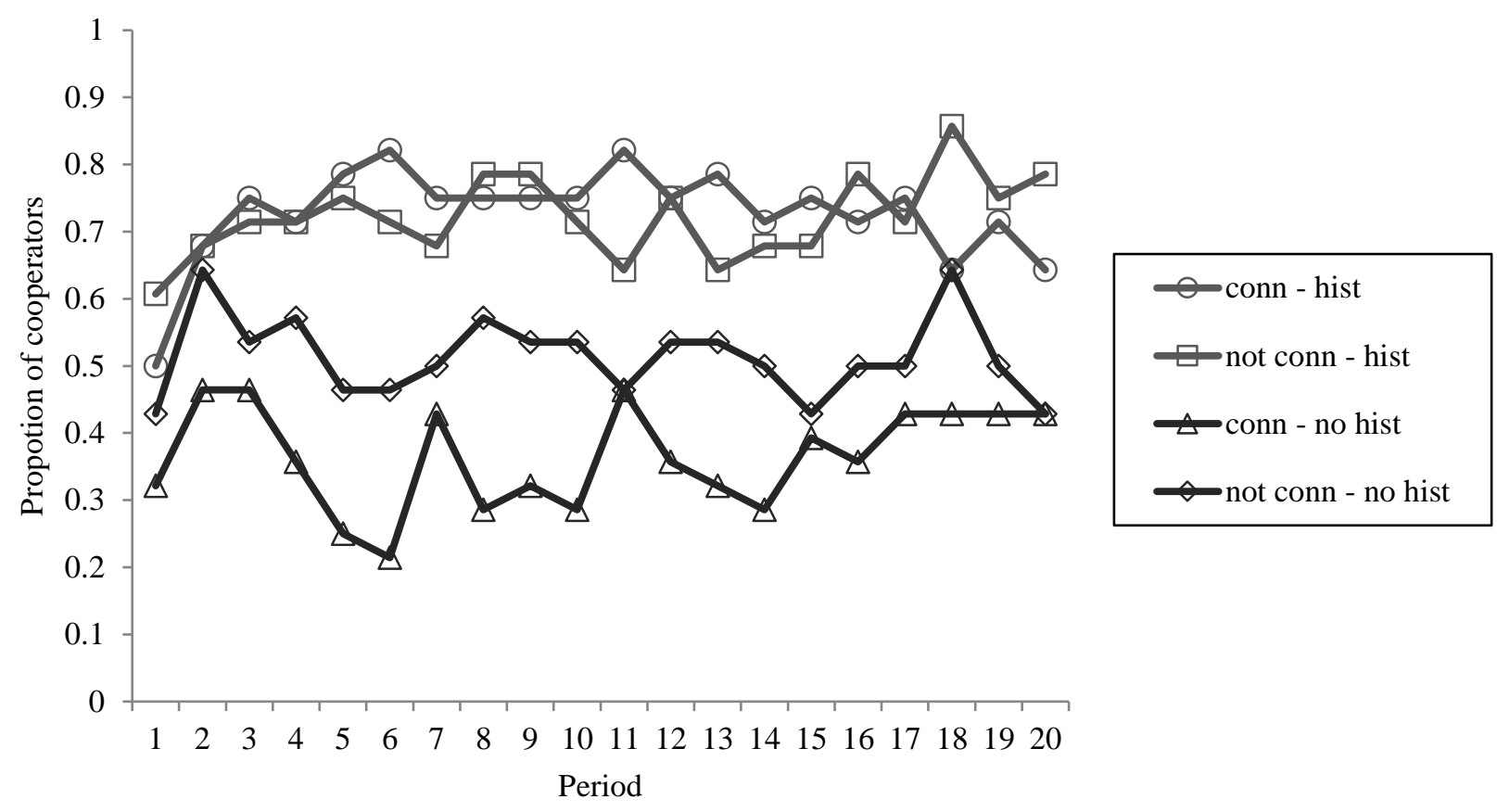

(b)

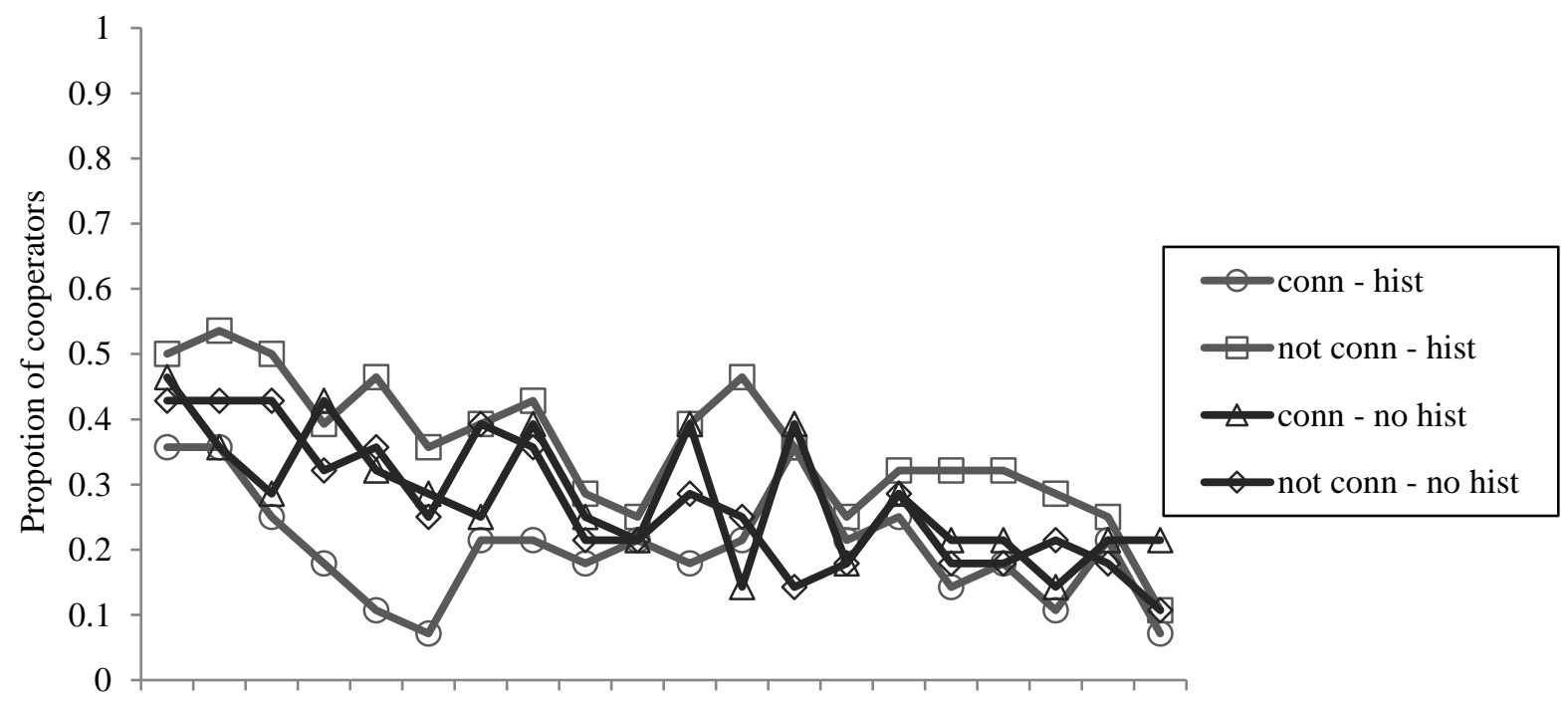

$\begin{array}{llllllllllllllllllll}21 & 22 & 23 & 24 & 25 & 26 & 27 & 28 & 29 & 30 & 31 & 32 & 33 & 34 & 35 & 36 & 37 & 38 & 39 & 40\end{array}$

Period 
Figure 3: The number of subjects choosing the modal group action in the (a) coordination game (periods 1 to 20) and (b) social dilemma (periods 21 to 40).

(a)

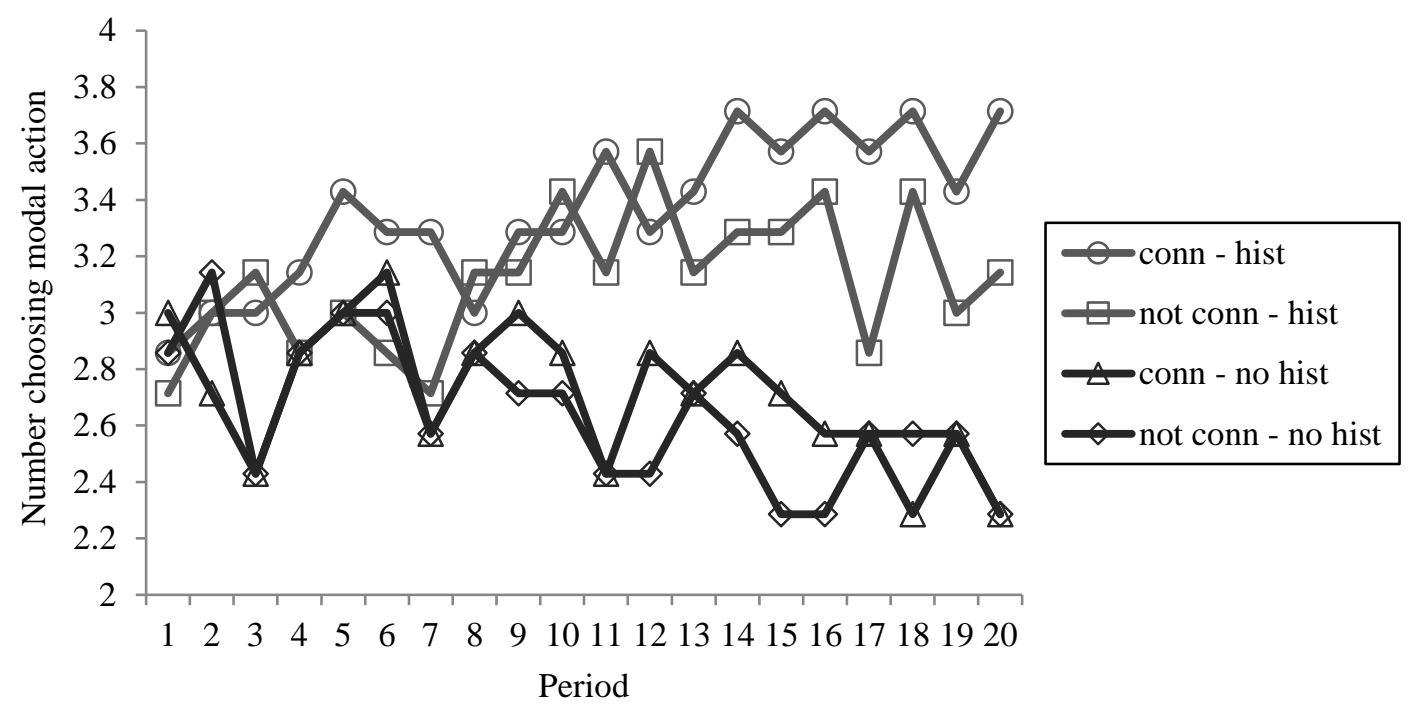

(b)

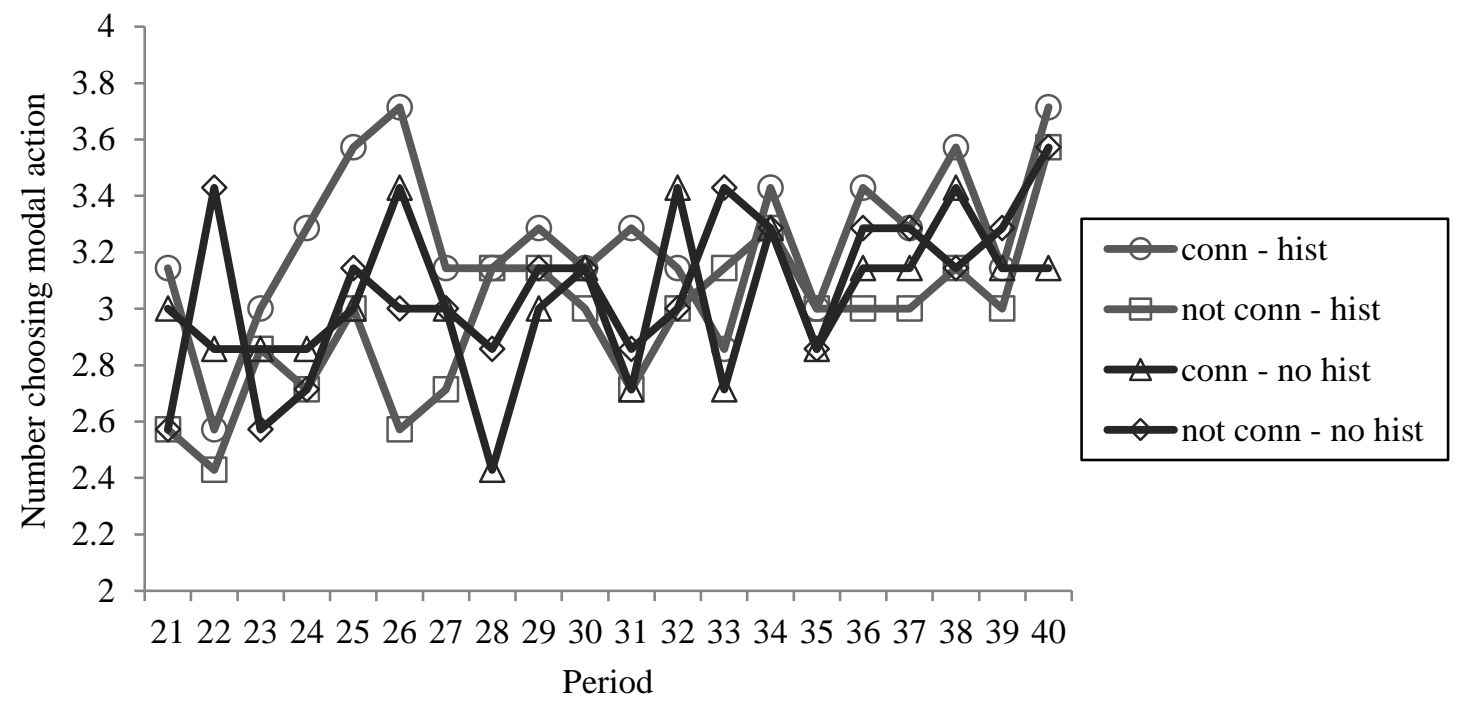

A lack of effect in the aggregate level of cooperation does not, in itself, mean there was no correlation of behaviour within groups. Figure 3 plots the number of group members choosing the modal action in the group. This can range from two, minimal correlation, to four, maximal correlation. We complement Figure 3 with Figure 4 which plots the proportion of subjects who 
coordinate with their match in that period, i.e. mutually choosing to cooperate or mutually choosing to not cooperate.

Figure 4: The proportion of subjects who coordinate with their match in that period in the (a) coordination game (periods 1 to 20) and (b) social dilemma (periods 21 to 40).

(a)

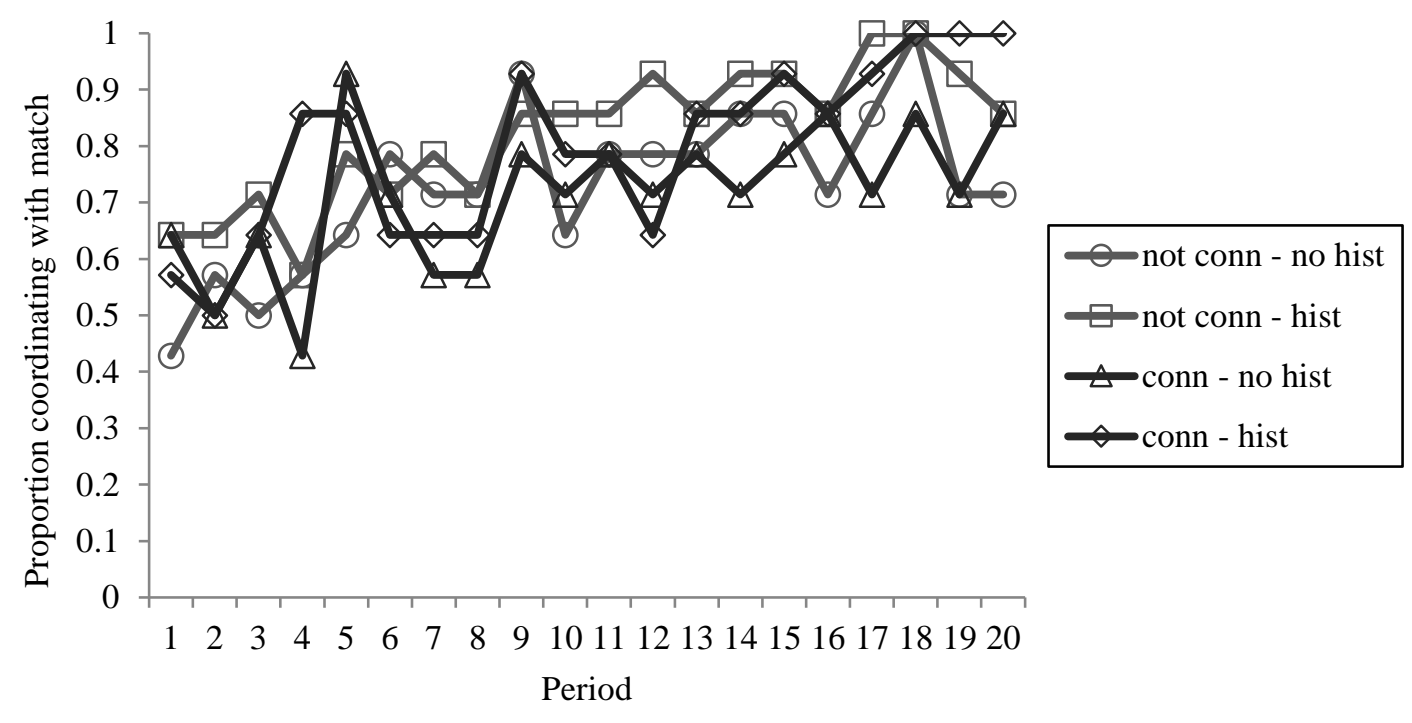

(b)

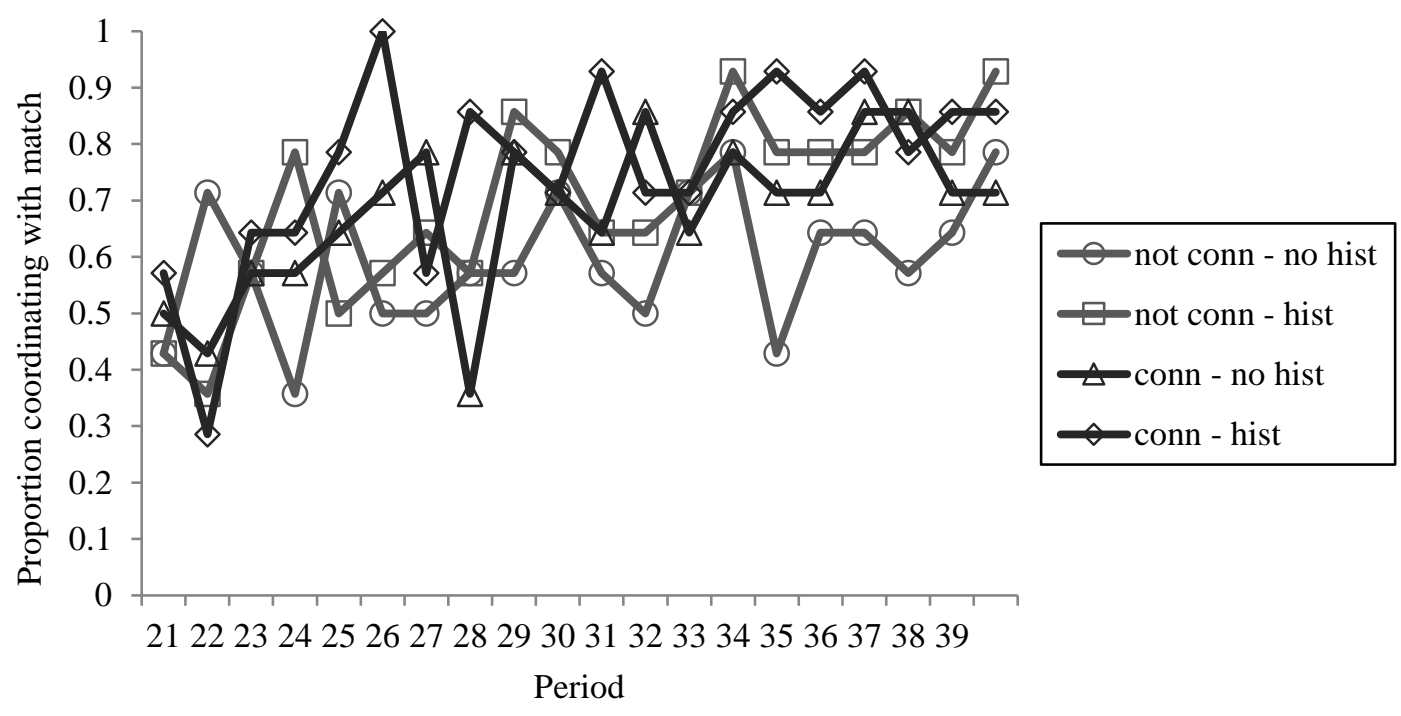


In the coordination game we see a noticeable difference between the history treatments and no history treatments in terms of correlation within the group (Figure 3a). This difference is significant $\left(\mathrm{p}=0.03\right.$, Mann-Whitney) particularly if we look at the final 10 periods $(\mathrm{p}=0.002) .{ }^{16}$ There is no difference across treatments in terms of coordination within matches (Figure 4a) with coordination increasing over time. Coordination within pairs is to be expected (Devetag and Ortmann 2007, Falk et al. 2013). The key issue for us is whether behaviour becomes homogenous across the group. In the no history treatments this does not happen. So, we often end up with one pair who mutually cooperate and another who do not cooperate (Figure 3a). This is evidence against a contagion effect. ${ }^{17}$ By contrast, in the history treatments we observe increased homogeneity within the group. This is evidence of an observations effect.

If we turn our attention to the social dilemma then we see both increased correlation within the group (Figure 3b) and coordination within pairs (Figure 4b). There are no significant differences between treatments $(\mathrm{p}>0.1)$. The increased correlation within groups could be seen as evidence as social interaction effects (see, in particular, Fowler and Christakis 2010). Again, however, there is no evidence of either a contagion or observations effect. Instead, we appear to simply be picking up a convergence towards non-cooperation. In particular, we observe high correlation across the group even in the benchmark treatment.

It is apparent in Figure 3 that correlation within the group evolves over the 40 periods. Figure 5 provides details on respective group outcomes in the final period, period 20 and $40 .{ }^{18}$ In the coordination game we again see a noticeable difference between the history treatments and the no-history treatments. In the history treatments, for instance, over 40 percent of the groups have all members cooperating, while in the no history treatments the proportion drops to zero percent $(p=0.02$, LR test). Interestingly, however, the proportion of times we observe one pair cooperate and the other non-cooperate is not significantly different across treatments $(p=0.12)$. We observe, therefore, more instances of maximum correlation in the history treatments, but not significantly

\footnotetext{
${ }^{16}$ There is no significance difference between the two connected treatments and the not-connected treatments, even in the final 10 periods $(\mathrm{p}>0.1)$. To be more specific: There is no significant difference in the final 10 periods between the connected and history and not-connected and history treatments $(\mathrm{p}=0.30$, Mann-Whitney). The differences between the not-connected, history and no history treatments $(p=0.05)$ and the connected, history and no history treatments $(\mathrm{p}=0.01)$ are significant.

17 The fact that we obtain groups with one pair who cooperate and another who do not cooperate means that there was potential for a contagion effect to appear.

${ }^{18}$ We did not observe any significant end game effect and so the picture remains the same in proceeding periods.
} 
more instances of zero correlation. We shall return to this point shortly. In the social dilemma game there are no significant differences between treatments.

Recall that all subjects played the social dilemma after playing the coordination game (with a different group). This raises the question of whether the differences we observe between the coordination game and social dilemma reflect an order effect. There are two reasons that we think our results are not being driven by an order effect. First, the cooperation level we obtain in the social dilemma is very similar to that observed in other studies (Fischbacher and Gächter 2010, Fowler and Christakis 2010). Second, it seems hard to argue that an order effect would result in no difference in part 2 of the experiment. ${ }^{19}$ We would argue, therefore, that there is some systematic reason why we observe an observations effect in the coordination game but not social dilemma. Is to such issues we now turn.

Figure 5. Group outcomes in the final period of the coordination game and social dilemma, distinguishing between all four cooperating (all cooperate), one pair of mutual cooperation and one of mutual non-cooperation (pairwise correlation) and all non-cooperate.

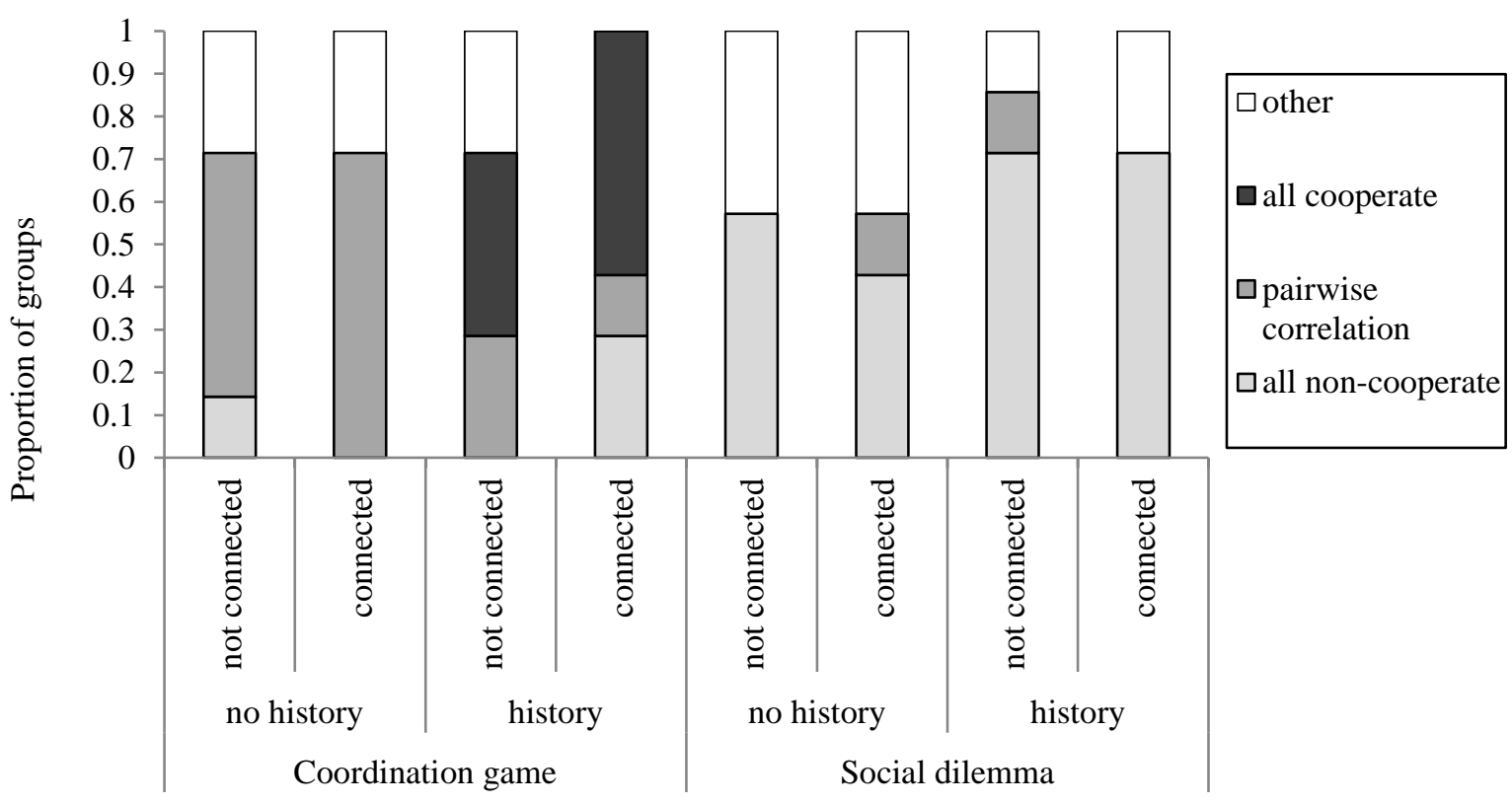

\footnotetext{
${ }^{19}$ It would be much harder, for instance, to rule out an order effect if we observed an observations effect in the social dilemma similar to that in the coordination game.
} 


\subsection{Contagion effect}

The lack of a contagion effect suggests that a subject, in a connected treatment, must adapt choice relative to the current match. That is, cooperating with one group member and not-cooperating with another. This is something that Berninghaus, Neumann and Vogt (2014) refer to as a mixed strategy. In order to more formally look for evidence of a mixed strategy, let $c_{i}^{t} \in\{0,1\}$ denote whether subject $i$ cooperated in period $t$, where $c_{i}^{t}=1$ indicates that the subject cooperated and $c_{i}^{t}=0$ that he or she did not. The value $\Delta_{i}^{t}=c_{i}^{t}-c_{i}^{t-1}$ tells us how subject $i$ changes behaviour between periods $t$ and $t-1$. For example, if the subject does not cooperate in period 11 and cooperates in period 12 then $\Delta_{i}^{12}=1$. Let $c_{-i}^{t} \in\{0,1\}$ denote whether the match of subject $i$ cooperated in period $t$ and let $\Delta_{-i}^{t}=c_{-i}^{t}-c_{-i}^{t-1}$ denote the change in behaviour. For example, if a subject's match did not cooperate in period 9 and cooperated in period 10 then $\Delta_{-i}^{10}=1$.

Consider the connected treatments. A mixed strategy would suggest a positive correlation between $\Delta_{i}^{t}$ and $\Delta_{i}^{t-2}$. To explain this point, suppose that subject $i$ was group member $A$ and $\Delta_{i}^{12}=$ 1 and $\Delta_{-i}^{10}=1$. Then subject $i$ did not cooperate in period 11 when interacting with member $B$ and cooperated in period 12 when interacting with member $C$. This fits with the behaviour subject $i$ last experienced when interacting with these group members - member $B$ not cooperating in period 9 and member $C$ cooperating in period 10. Figure 6 plots $\Delta_{i}^{t}$ against $\Delta_{-i}^{t}$ with the radius of the circle measuring the proportion of observations of each type. In the connected treatments we see a positive relationship between differences in own choice and others choice for both the coordination game and social dilemma. This is evidenced by a higher proportion of $(-1,-1)$ and $(1,1)$ pairs compared to $(-1,1)$ and $(1,-1)$ pairs. These differences are highly significant $(\mathrm{p}<$ 0.01 , LR test) and evidence of a mixed strategy.

For comparison we also plot the data for the not-connected treatments where, as expected, there is no correlation between $\Delta_{i}^{t}$ and $\Delta_{-i}^{t}$. Also worth comment, is that in the connected treatments a sizable proportion of subjects choose the same action against both other group members (see the large number of $(-1,0)$ and $(1,0)$ pairs). This is not evidence of a contagion effect, even in the coordination game, because it may reflect a subject's expectation that others will change action. ${ }^{20}$

\footnotetext{
${ }^{20}$ If member A cooperates and member B non-cooperates then only one of them needs to change choice in order to coordinate next time around.
} 
Figure 6: Correlation between own cooperation and previous opponent's cooperation in odd and even periods. The size of the circle measures the proportion of observations of this type.

(a) Connected treatments, coordination game (left) and social dilemma (right)
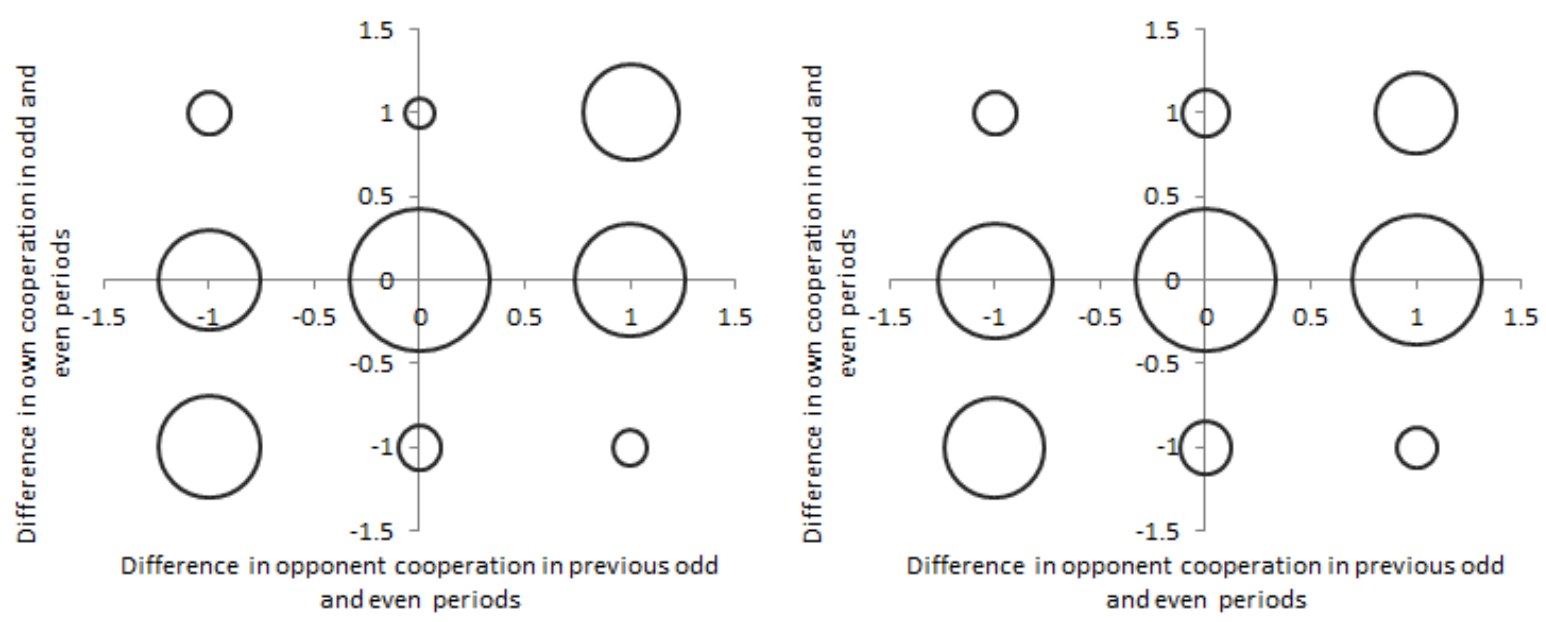

(b) Not-connected treatments, coordination game (left) and social dilemma (right)
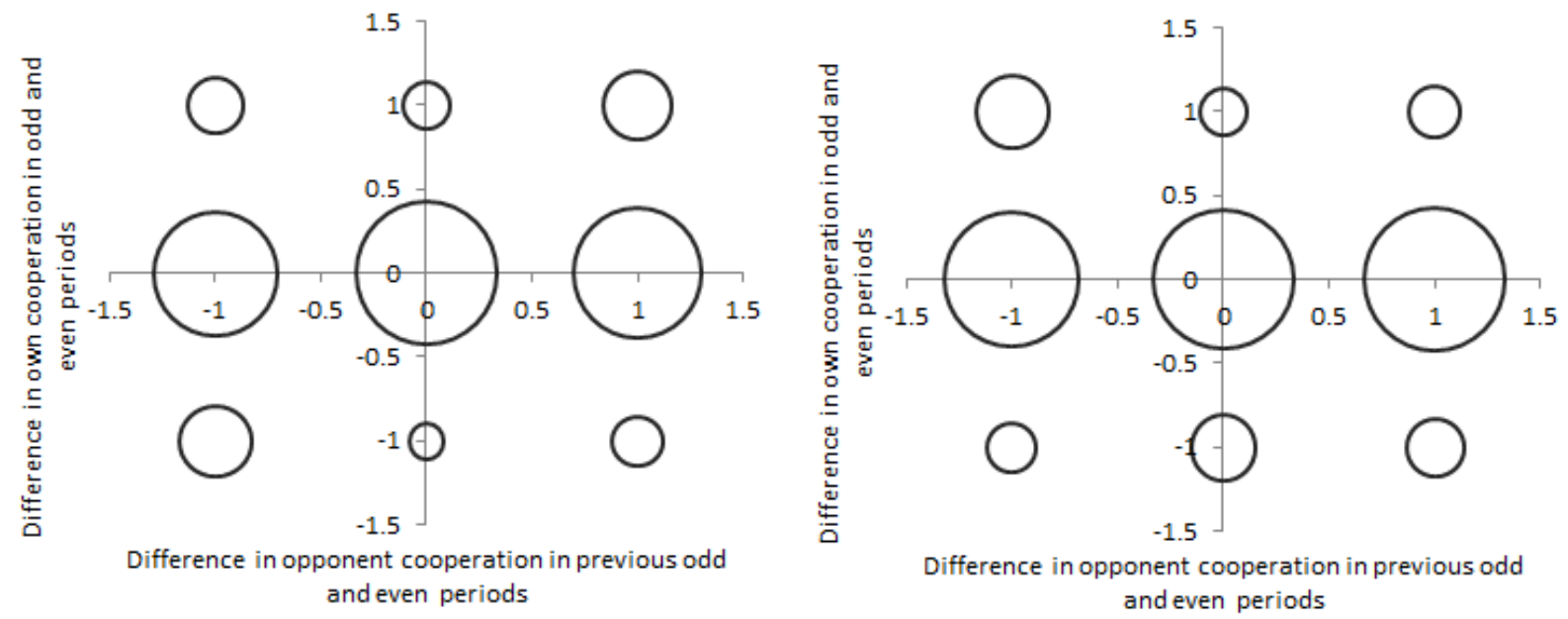

\subsection{Observation effect}

As we have discussed an observations effect can broadly represent social preferences or social learning. The differences we observe between the coordination game and social dilemma, coupled with a lack of contagion effect, suggest that social learning is the more likely factor in our experiment. In particular, the willingness of subjects to condition action on the current opponent is evidence of relatively strategic behavior. Observing others may, therefore, have acted as a kind 
of 'sun spot' that facilitated coordination through a convergence in beliefs. This clearly points more towards social learning than social preferences. To explain the point we provide an example.

Consider, first, a not-connected treatment and suppose the A-B pair mutually cooperate while member $C$ cooperates and member $D$ does not cooperate. If history is not observable then members $C$ and $D$ cannot see the mutual cooperation in the A-B pair. Ultimately, the C-D pair will likely coordinate but it is unclear whether they will coordinate on the efficient or inefficient equilibrium. Suppose now that history is observable. In this case member's $C$ and $D$ can see the mutual cooperation in the A-B pair. Intuitively, this makes it more likely the C-D pair will coordinate on mutual cooperation. The A-B pair provides 'an example' to follow. Moreover, the cooperation of the A-B pair provides a focal piece of information to aid coordination of the C-D pair. In particular, it may change the beliefs of member D on the likelihood of achieving mutual cooperation.

That observing others can serve as a focal point is consistent (recall Figure 4) with the fact that subjects were no more likely to coordinate in the history treatments compared to the no-history treatments, they were just more likely to coordinate on the efficient equilibrium. To provide some more direct evidence see Figure 7. This details the proportion of groups in which the level of cooperation stays the same or increases from one period to the next. Of key importance is what happens if there are three group members cooperating in the coordination game. Consistent with the story of the previous paragraph, it is significantly more likely that there will be a weak increase in cooperation in a history compared to a no-history treatment ( $\mathrm{p}=0.03, \mathrm{LR}$ test). A similar effect is also seen in the social dilemma, although this effect is statistically insignificant $(p=0.21)$.

In the case where two group members cooperate we observe no significant difference between the history and no-history treatments $(\mathrm{p}>0.1)$. This is as we would expect. More interesting is the case where one group member cooperates. Somewhat surprisingly, it is more likely that there will be an increase in cooperation in the history compared to no-history treatments $(\mathrm{p}=0.08, \mathrm{LR}$ test). Given that it was relatively rare to see only one cooperator we have too few observations to decompose why this was the case. We can say, however, that across treatments, the unique cooperator typically remained a cooperator in the subsequent period. Moreover, the difference we observe in Figure 7 is driven by the connected and history treatment where a player has an incentive to take note of what happened in the other pair (because he will be matched with one of the pair in the next period). 
Figure 7: The proportion of times where the level of cooperation in the group stays the same or increases from one period to the next conditional on the number initially cooperating.

(a) Coordination game

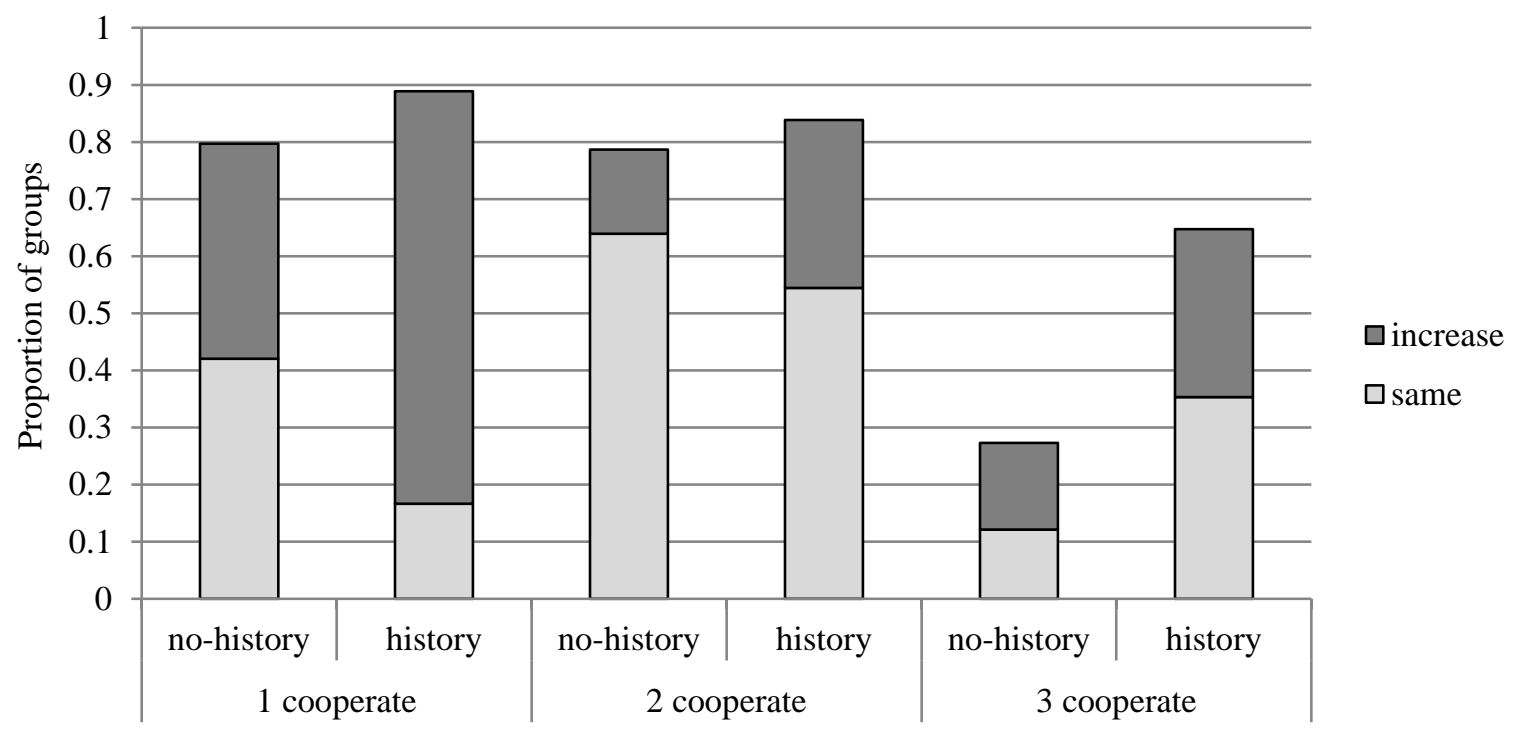

(b) Social dilemma

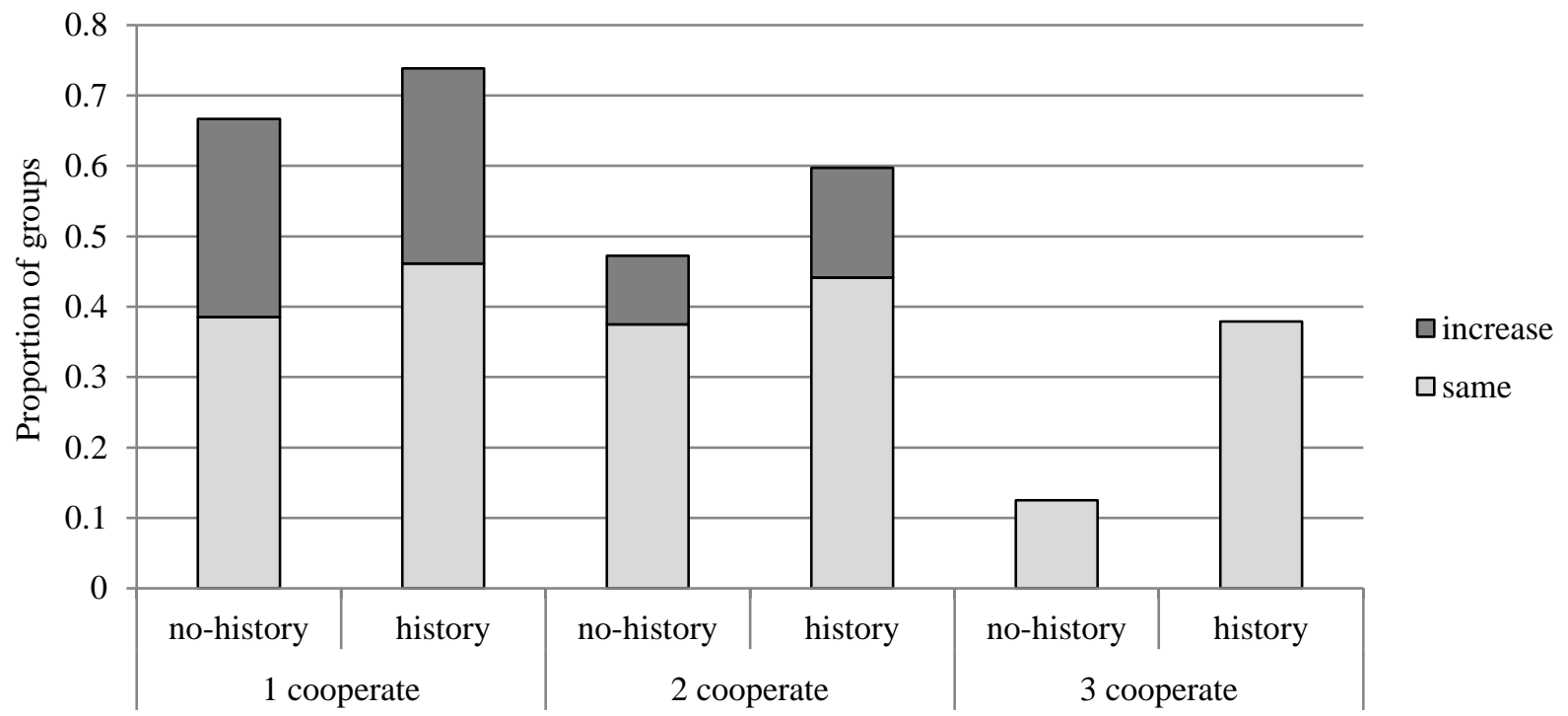

In summary, the choices we observe in the coordination game are consistent with strategic behavior. The observations effect may well, therefore, reflect members using information on others 
as a 'sun spot' around which to coordinate through convergence of beliefs. This can explain the higher levels of coordination and cooperation we observed in the history treatments. It also can explain why we found no observations effect in the social dilemma. More specifically, the choices we observe in the social dilemma are also consistent with strategic behavior but merely result in a familiar convergence on the dominant strategy of non-cooperation. This interpretation of the observations effect suggests social learning, rather than something social preferences, is causing the effect. We would argue, however, that this is still an endogenous social interactions effect.

\section{Discussion}

In this paper we have reported on an experiment designed to disentangle two possible sources of endogenous social interactions effect. The distinction is made between an observations effect, which comes from observing others over time, and a contagion effect, which comes from indirectly interacting with others over time. We find no evidence of a contagion effect. We find strong evidence of an observation effect in a coordination game, but not a social dilemma.

The absence of any contagion effect is consistent with the results of Falk et al. (2013) and Berninghaus, Neumann and Vogt (2014). They also observe subjects choosing a different action depending on the opponent, meaning little spillover from one interaction to another. ${ }^{21}$ We highlight that this lack of spillover has important implications for the interpretation of results, both theoretical and experimental, on learning across networks (e.g. Morris 2000, Berninghaus et al. 2002, Cassar 2007). The literature typically assumes (or in the experimental context, forces) an individual to choose the same action in all interactions. Spillovers are thus exogenously imposed making some form of contagion effect inevitable. The generality of this assumption and the associated results may need rethinking if spillovers are not common in practice.

We have treated the lack of a spillover effect as evidence against a contagion effect. It is, therefore, important to clarify that subjects adapting their behaviour to that of an opponent can also be taken as evidence of an endogenous social interactions effect. This is the interpretation Falk et al. (2013) use in analyzing their results. This distinction largely comes from how one defines the group. Our approach considers pair-wise interactions within a group of four. The group

\footnotetext{
${ }^{21}$ Bednar et al. (2012) do find a spillover effect from one game to another but in this case a subject is playing two different types of game. The effect is thus best explained by cognitive load. See also Savikhin and Sheremeta (2013).
} 
is thus 'larger' than any game played. By contrast, Falk et al. (2013) equate group with game and so see a person as simultaneously interacting with two different groups. ${ }^{22}$ Given that social interactions effects are typically motivated by the idea people conform to behaviour within the group (Blume et al. 2004) this distinction is not innocuous.

The results of Falk et al. (2013) show that people can be influenced by those with whom they directly interact. This is understandable through strategic motives, even if those motives may reflect social preferences such as reciprocity or inequity aversion (Gäcther et al. 2013). Our findings are consistent with those of Falk et al. (2013) in this regard. In understanding social interactions effects, though, it seems particularly important to question whether people are influenced by those with whom they do not directly interact. In order to address this question subjects need exposure, as some did in our experiment, to what is going on in a more broadly defined group. This is the approach typical in the literature looking at peer effects (e.g. Fortin et al. 2007, Gächter et al 2013). ${ }^{23}$

Given that we have strong evidence for an observations effect we see that subjects can be influenced by others in the group. We have suggested, however, that information about others served a relatively strategic purpose in helping facilitate coordination. There was no evidence of 'blind' conformity to group norms. In this regard our findings are consistent with prior results. Cooper and Rege (2011), for instance, find evidence of endogenous effects but put this down to social regret rather than social learning or conformity. Similarly, Gächter, Nonsenzo and Sefton (2013) find evidence consistent with social preferences rather than conformity to social norms. See also Fortin et al. (2007) who find that evidence of endogenous interaction effects disappears in their data once an appropriate empirical strategy is used.

Recall that our basic objective in this paper was to distinguish different possible sources of endogenous effect. Our results, coupled with those in the literature that we have just mentioned, suggest they are not driven by contagion or conformity. This is not to deny endogenous effects exist; we clearly observed endogenous effects in our data. It does though suggest the extent of endogenous social interactions effects in the general population may be overstated or the causes of any effects misattributed. For instance, the highly correlated behavior we observed in the social

\footnotetext{
${ }^{22}$ Falk et al (2013) consider a 'population' of nine people. Each person in that population plays in two distinct three player games with a total of four different people. One can think of the group as the nine people in the population or as the three people in any one game.

${ }^{23}$ See also Blume et al. (2011) who discuss the importance and difficulty of describing 'group'.
} 
dilemma is most easily explained as an exogenous effect. Our experimental design allows us to rule out an endogenous contagion effect (Fowler and Christakis 2010).

\section{References}

Antonioni A., Cacault M.P., Lalive, R., Tomassini, M. (2013). Coordination on Networks: Does Topology Matter? PLoS ONE 8(2): e55033.

Bednar, J., Chen, Y., Liu, T. X., \& Page, S. (2012). Behavioral spillovers and cognitive load in multiple games: An experimental study. Games and Economic Behavior, 74(1), 12-31.

Berninghaus, S.K., Ehrhart, K.M., \& Keser, C. (2002) Conventions and local interaction structures: experimental evidence. Games and Economic Behavior 39: 177-205.

Berninghaus, S. K., Neumann, T., \& Vogt, B. (2014) Learning in networks: An experimental study using stationary concepts Games 5: 140-159.

Bicchieri, C. (2018). Norms in the wild: How to diagnose, measure, and change social norms. Oxford University Press.

Blume, L, Brock, W., Durlauf, S. and Ioannides, Y. (2011). "Identification of Social Interactions," in Jess Benhabib, Matthew O. Jackson and Alberto Bisin (editors): Handbook of Social Economics, Vol. 1B, The Netherlands: North-Holland, 2011, pp. 853-964.

Blume, L., \& Durlauf, S. (2004). The interactions-based approach to socioeconomic behavior. Social dynamics, S. Durlauf and P. Young (Eds.), MIT Press.

Blume, L. E., \& Durlauf, S. N. (2006). Identifying social interactions: A review. Methods in social epidemiology, J.M. Oakes \& J.S. Kaufman (Eds.), John Wiley \& Sons.

Boyer, T., \& Jonard, N. (2014). Imitation and efficient Contagion. Journal of Economic Behavior \& Organization.

Brock, W. A., \& Durlauf, S. N. (2001). Discrete choice with social interactions. The Review of Economic Studies, 68(2), 235-260.

Cason, T. N., Savikhin, A. C., \& Sheremeta, R. M. (2012). Behavioral spillovers in coordination games. European Economic Review, 56(2), 233-245.

Cassar A. (2007) Coordination and cooperation in local, random and small world networks: Experimental evidence. Games and Economic Behavior, 58: 209-230.

Castillo, M., and Carter, M. (2007). "Identifying Social Effects with Economic Experiments", working paper, Georgia Institute of Technology and University of Wisconscon-Madison.

Cooper, D. J., \& Rege, M. (2011). Misery loves company: social regret and social interaction effects in choices under risk and uncertainty. Games and Economic Behavior, 73(1), 91-110.

Devetag, G., \& Ortmann, A. (2007). When and why? A critical survey on coordination failure in the laboratory. Experimental Economics, 10(3), 331-344.

Duffy, J., \& Ochs, J. (2009). Cooperative behavior and the frequency of social interaction. Games and Economic Behavior, 66(2), 785-812. 
Duflo, E., \& Saez, E. (2003). The role of information and social interactions in retirement plan decisions: Evidence from a randomized experiment. The Quarterly Journal of Economics, $118(3), 815-842$.

Dufwenberg, M., \& Kirchsteiger, G. (2004). A theory of sequential reciprocity. Games and Economic Behavior, 47(2), 268-298.

Durlauf, S. N. (2002). On The Empirics Of Social Capital. The economic journal, 112(483), F459-F479.

Durlauf, S. N., \& Ioannides, Y. M. (2010). Social interactions. Annual Review of Economics, 2(1), 451-478.

Ellison, G. (2000). Basins of attraction, long-run stochastic stability, and the speed of step-bystep evolution. The Review of Economic Studies, 67(1), 17-45.

Falk, A., \& Ichino, A. (2006). Clean evidence on peer effects. Journal of Labor Economics, 24(1), 39-57.

Falk, A., Fischbacher, U., \& Gächter, S. (2013). Living in Two Neighborhoods-Social Interaction Effects in the Laboratory. Economic Inquiry, 51(1), 563-578.

Fischbacher, U. \& Gachter, S. (2010). Social Preferences, Beliefs, and the Dynamics of Free Riding in Public Goods Experiments. American Economic Review, 100(1), 541-56.

Fortin, B., Lacroix, G., \& Villeval, M. C. (2007). Tax evasion and social interactions. Journal of Public Economics, 91(11), 2089-2112.

Fowler, J. H., \& Christakis, N. A. (2010) Cooperative behavior cascades in human social networks. Proceedings of the National Academy of Sciences, 107(12), 5334-5338.

Frey V, Corten, R. \& Buskens, V. (2012) Equilibrium selection in network coordination games. Review of Network Economics 11: 1-26.

Gächter, S. Nonsenzo, D. \& Sefton, M. (2013) Peer effects in pro-social behavior: Social norms of social preferences. Journal of the European Economic Association 11: 548-573.

Graham, B. S. (2008). Identifying social interactions through conditional variance restrictions. Econometrica, 76(3), 643-660.

Keser C, K-M-Erhart, and Berninghaus S (1998) Coordination and local interaction: experimental evidence. Economics Letters 59: 269-275.

Manski, C. F. (1993). Identification of endogenous social effects: The reflection problem. The Review of Economic Studies, 60(3), 531-542.

Manski, C. F. (2000). Economic analysis of social interactions. Journal of Economic Perspectives 14(3): 115-136.

Morris, S. (2000). Contagion. The Review of Economic Studies, 67(1), 57-78.

Savikhin, A. C., \& Sheremeta, R. M. (2013). Simultaneous decision-making in competitive and cooperative environments. Economic Inquiry, 51(2), 1311-1323.

Shang, J., \& Croson, R. (2009). A field experiment in charitable contribution: The impact of social information on the voluntary provision of public goods. The Economic Journal, 119(540), 1422-1439. 
Thöni, C., \& Gächter, S. (2015). Peer effects and social preferences in voluntary cooperation: A theoretical and experimental analysis. Journal of Economic Psychology, 48, 72-88.

Weidenholzer, S. (2010) Coordination games and local interactions: a survey of the gametheoretic literature. Games 1: 551-585.

Young, H. P. (2009). Innovation diffusion in heterogeneous populations: Contagion, social influence, and social learning. The American Economic Review, 99: 1899-1924. 